\title{
5G TECHNOLOGY: A REVOLUTION IN MOBILE COMMUNICATION
}

\author{
Vyom Bhushan ${ }^{1}$, D. B. Salunke ${ }^{2}$ \\ ${ }^{I}$ Automobile Engineering, IOK COE, S. P. Pune University, Pune, Maharashtra, India \\ ${ }^{2} E \&$ TC Engineering, S. P. Pune University, Pune, Maharashtra, India
}

\begin{abstract}
5th Generation Mobile Technology is most commonly known as 5G Technology. In this paper, an effort to assess diverse current groups of mobile communication technology in terms of design, features, benefits, limitations and solicitations has been made along with marking out the progression and expansion of mobile communication technology along with their prominence and benefits of one over the other. A comprehensive study related to $5 G$ technology of mobile communication is the main objective of this paper. In 5G, researches are linked to the development of World Wide Wireless Web, Dynamic Ad-hoc Wireless Networks $(D A W N)$ and Real Wireless Communication.
\end{abstract}

Keywords: Evolution of Wireless Technologies, $5 G$ Architecture, Need of 5G, Features of 5G, WWWW

\section{INTRODUCTION}

Mobile and wireless networks have evolved immensely during last fifteen years. Presently, many mobile phones have a WLAN adapter. It is also expected that in very near future, several mobile phones will have Wi-MAX adapter along with their $3 \mathrm{G}, 2 \mathrm{G}$, WLAN, Bluetooth, etc. adapters. The main unique platform is Flat IP network. Certainly Flat IP network is the principal notion to make $5 \mathrm{G}$ suitable for all varieties of technologies.

\section{EVOLUTION OF WIRELESS}

\section{TECHNOLOGIES}

\subsection{G Mobile Communication System}

The mobile communication system which came into existence during the period of 1974 to 1984 , is generally known as $1 \mathrm{G}$. It was primarily established at an earlier point to interconnect with the mobile phones via linkage of circulated transceivers which could send and receive voice messages. The analogue system was used in the first mobile wireless communication system centered on more developed features.

AMPS structure was constructed on frequency variation radio system which permits only voice calls with network aptitude of $30 \mathrm{KHz}$ and occurrence band of range 824-894 $\mathrm{MHz}$ through Frequency Division Multiple Access (FDM) at a speed up to $2.4 \mathrm{Kbps}$.

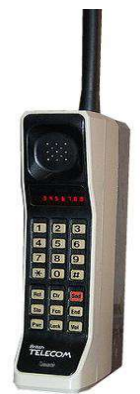

Fig-1: $1 \mathrm{G}$ Mobile Phone ${ }^{[1]}$

\subsection{G Mobile Communication System}

$2 \mathrm{G}$ refers to the second age bracket of mobile linkages which was the next step in the growth of mobile communication following 1G. 2G started in 1980's and finalized in 1990's and was primarily used for voice communication with digital indicators with speed up to 64 kbps.

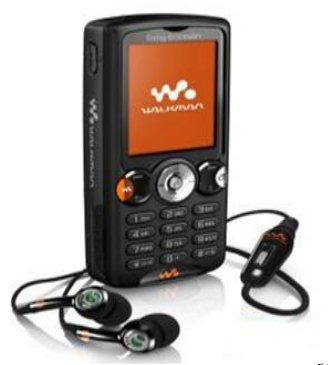

Fig-2: 2G Mobile Phone ${ }^{[1]}$

More advanced features like SMS and MMS were found in $2 \mathrm{G}$ in comparison to $1 \mathrm{G}$.

\subsection{G Mobile Communication System}

The next mobile communication system, which started in 2000 was given the name of $3 \mathrm{G}$. This system was more advanced as compared to the previous one. $3 \mathrm{G}$ network excludes various glitches.
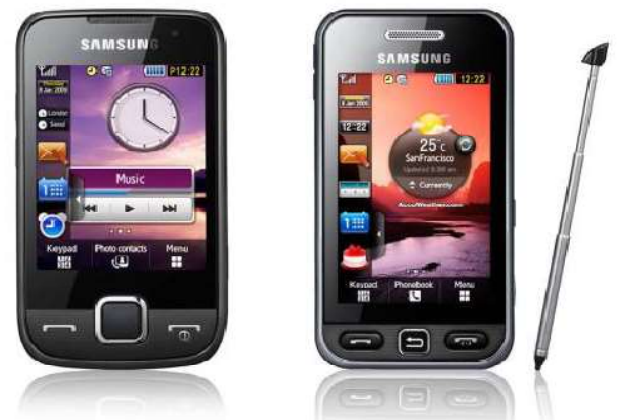

Fig-3: 3G Mobile Phone ${ }^{[1]}$ 
The substantial feature of $3 \mathrm{G}$ technology provides speedy data conduction rate with remarkable increase in proficiency. Packet-switching technology was efficiently used in $3 \mathrm{G}$.

$3 \mathrm{G}$ has following restrictions: 1) Faster bandwidth requirement, 2) High cost for the $3 \mathrm{G}$ mobile phone, 3) Larger phone size, 4)Intricate infrastructure for $3 \mathrm{G}, 5$ ) Costlier 3G License Services.

\subsection{G Mobile Communication System}

The next generation mobile communication started in 2010 was called as $4 \mathrm{G}$. It has IP-based mobile system which proposes access via assortment of radio interfaces at speed range 100-1 Gbps.

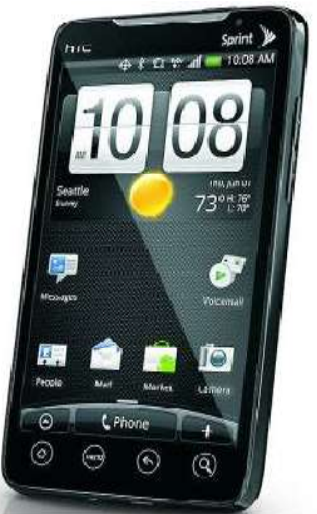

Fig-4: 4G Mobile Phone ${ }^{[1]}$

The main features of this technology is video conferencing and its other features include rapidity and inter-operability.

Restrictions of 4G are: 1) Quick Battery drainage, 2) Challenging implementation of hardware, 3) Complex hardware requirement. 4) Pressure of high-class network for the employment of the next generation network.

\subsection{G Mobile Communication System}

5G Mobile Communication System is nothing but the recent advance fifth cohort wireless internet network which is retained by several networks such as IPv6 and OFDM.

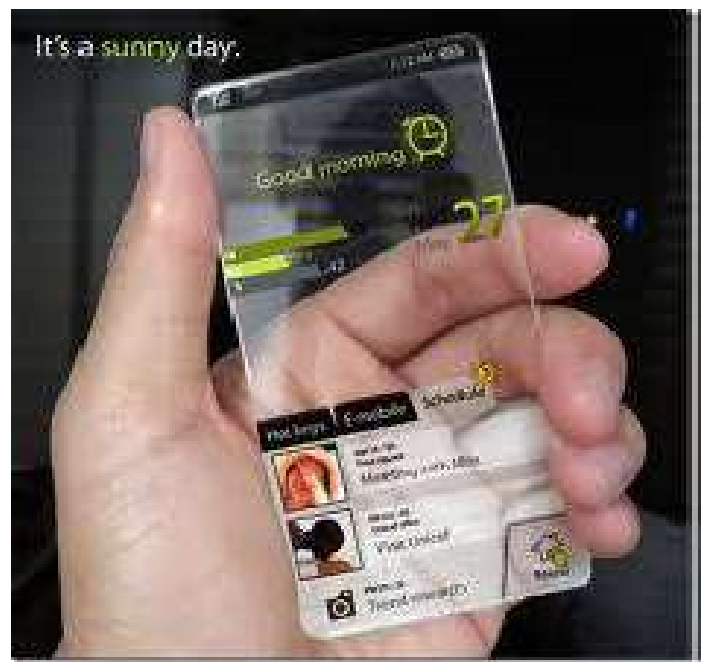

Fig-5: 5G Mobile Phone ${ }^{[1]}$

The wireless technology in $5 \mathrm{G}$ is demarcated by the physical layer and data link layer. 5G technology is described by these two layers. The $5 \mathrm{G}$ depots will have software distinct radios and variation outlines along with latest error-control structures that can be transferred from the Internet.

The expansion is realized towards the user depots as a target of the $5 \mathrm{G}$ mobile networks with virtual multi-wireless network maintenance. The network layer is sub divided into upper network layer and interface where all the routing is based on IP addresses which is unique for each user across the world. A common platform is the basic requirement to make 5G applicable for all sorts of radio access technologies. ${ }^{[8]}$

\section{COMPARISION OF ALL GENERATIONS OF MOBILE TECHOLOGIES}

Table 1 Comparison of All Generations of Mobile Technologies ${ }^{[4]}$

\begin{tabular}{|c|c|c|c|c|c|}
\hline $\begin{array}{c}\text { Technology } \rightarrow \\
\text { Features } \\
\downarrow\end{array}$ & IG & $2 \mathbf{G}$ & $3 G$ & $4 G$ & SG \\
\hline Start/ Deployment & $1970-1980$ & $1990-2004$ & $2004-2010$ & Now & $\begin{array}{l}\text { Soon (probably } \\
2020 \text { ) }\end{array}$ \\
\hline Data Bandwidth & $2 \mathrm{kbps}$ & $64 \mathrm{kbps}$ & 2Mbos & 1 Gbps & Higher than 1Gbps \\
\hline Techmology & $\begin{array}{l}\text { Analog Cellular } \\
\text { Technology }\end{array}$ & $\begin{array}{l}\text { Digital Cellular } \\
\text { Technology }\end{array}$ & $\begin{array}{l}\text { CDMLA } 2000 \\
\text { (IXRTT. } \\
\text { EVDO) } \\
\text { UNIS, EDGE }\end{array}$ & $\begin{array}{l}\text { WiMax LTE } \\
\text { Wi-Fi }\end{array}$ & wwww(coming soon) \\
\hline Service & $\begin{array}{l}\text { Mobile Telephony } \\
\text { (Voice) }\end{array}$ & $\begin{array}{l}\text { Digital voice, } \\
\text { SMS, Higher } \\
\text { capacity } \\
\text { packetized data }\end{array}$ & $\begin{array}{l}\text { Integrated high } \\
\text { quality audio. } \\
\text { video and data }\end{array}$ & $\begin{array}{l}\text { Dynamic Information } \\
\text { access, Wearable } \\
\text { devices }\end{array}$ & $\begin{array}{l}\text { Dynamic Information } \\
\text { access, Wearable } \\
\text { devices with AI } \\
\text { Capabilities }\end{array}$ \\
\hline Multiplexing & FDMA & TDMA, CDMA & CDMA & CDMA & CDMA \\
\hline Switching & Circuit & Circuit, Packet & Packet & All Packet & All Packet \\
\hline Core Network & PSTN & PSTN & Packet N/W & Internet & Internet \\
\hline
\end{tabular}




\section{5G SYSTEM ARCHITECTURE}

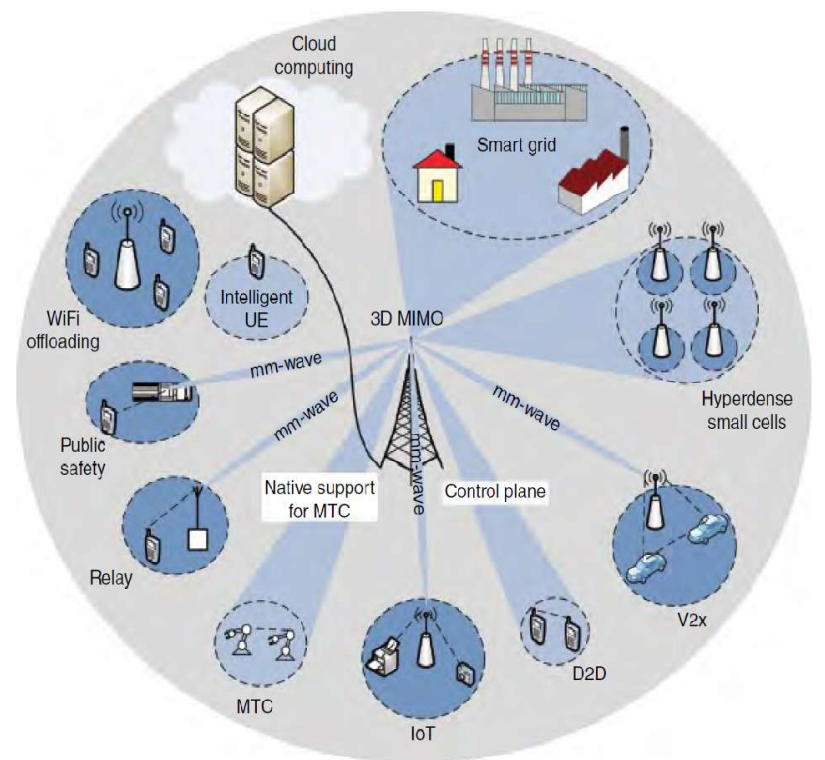

Fig-6: 5G System Architecture ${ }^{[2]}$

$5 \mathrm{G}$ will be a truly converged system supporting a wide range of applications from mobile voice and multi Giga-bit per second mobile Internet to D2D and V2X communications, as well as native support for MTC and public safety applications. ${ }^{[2]}$

The integration of the 3D-MIMO can be done at BSs up to the level of macro-cell for the improvement in data rate and capacity. The performance of the system can be enhanced for capacity and coverage in dead-spot and hot-spot having relay stations.

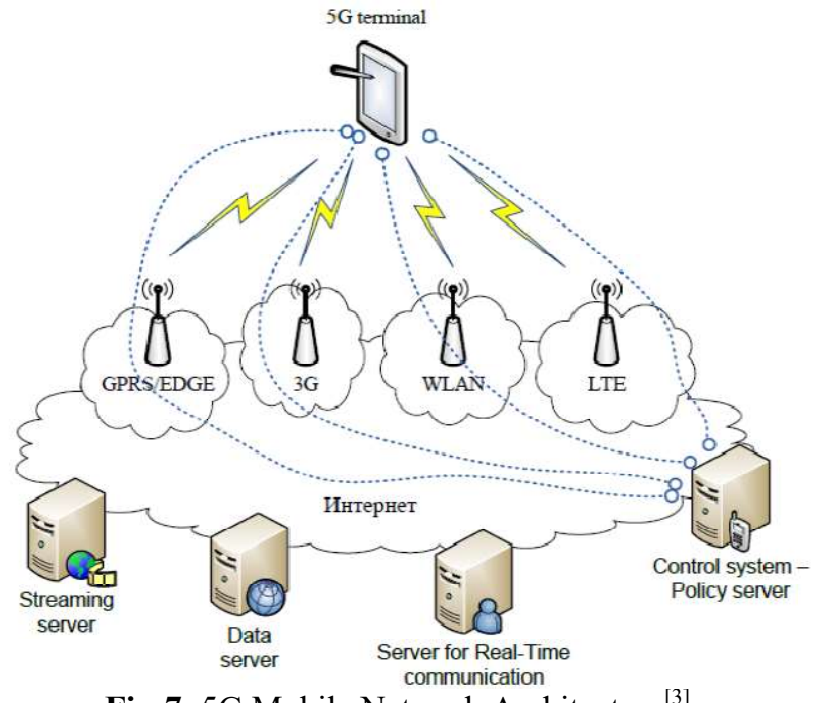

Fig-7: 5G Mobile Network Architecture ${ }^{\lfloor 3\rfloor}$

Cloud computing can potentially be applied to the RAN, and to mobile users that can form a virtual pool of resources to be managed by the network. ${ }^{[2]}$ Through the cloud, the application can be brought closer to the end user by reducing the latency in communication for supporting the control applications of delay-sensitive real-time.

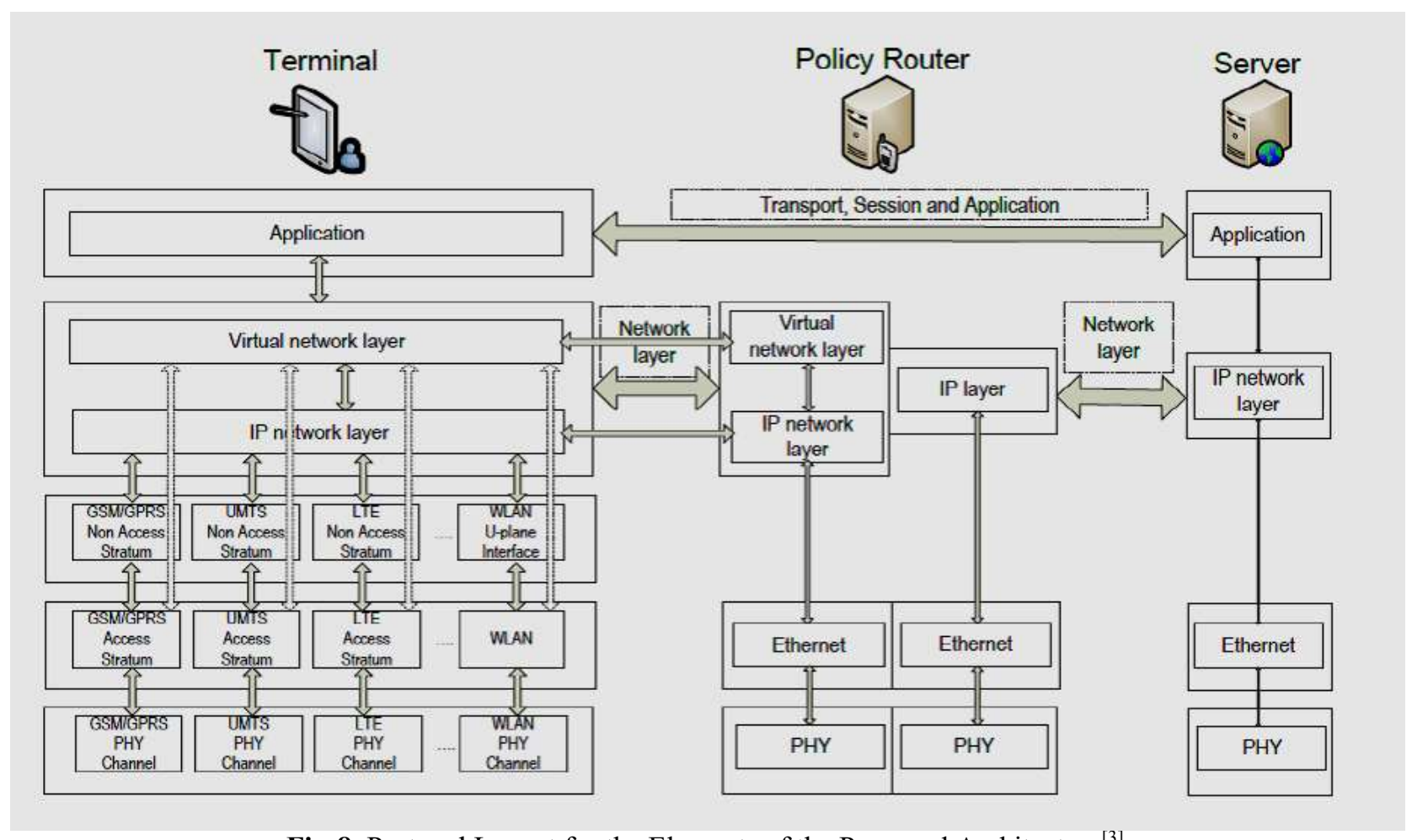

Fig-8: Protocol Layout for the Elements of the Proposed Architecture ${ }^{[3]}$ 
Smart grid is also a remarkable application visualized for $5 \mathrm{G}$, allowing the electricity grid to work in a more consistent and well-organized manner.

\section{NEED OF 5G TECHNOLOGY}

The need of $5 \mathrm{G}$ technology includes:

- Spectral efficiency of the system must be high.

- Availability of high data rates at cell edge and a better coverage.

- Battery consumption should be lower.

- It is desirable to keep higher data rate in mobility up to 1 Gbps.

- Beam antenna systems must be intelligent.

- Traffic fees should be cheaper.

- The web applications which are wireless-based and have multimedia capability higher than $4 \mathrm{G}$ speeds are needed.

- Data transfer paths should be multiple and concurrent.

- High cognitive radio/SDR Security.

- Outage probability should be lower.

- It should not harm human life.

\section{FEATURES OF 5G TECHNOLOGY}

The 5G technology has following features:

- $5 \mathrm{G}$ technology has zero order error due to its high quality technology.

- It facilitates better supervision and fast action.

- This technology is more attractive and effective due to advanced billing interfaces.

- It has high connectivity speed nearly $25 \mathrm{Mbps}$.

- It has very high speed of uploading and downloading.

- It is more accurate in comparison to other technologies.

- $5 \mathrm{G}$ technology offers large data broadcasting in Gigabytes.

- It provides high resolution for passionate mobile phone users.

- It supports virtual private network.

- It has high consistency and gives the gateway of transporter class.

- It gives better and fast solution due to remote management.

- It has a special feature of remote diagnostics.

\section{ADVANTAGES OF 5G TECHNOLOGY}

The following are advantages of 5G technology:

- Uploading of pages can be done in a very fast manner.

- It can download the files very fast.

- The battery runs for a longer time.

- $5 \mathrm{G}$ devices are less costly than in comparison to $3 \mathrm{G}$ and $4 \mathrm{G}$ devices.

- One platform would be enough to collect all networks.

- It is compatible with all earlier generations.

- It supports all the new services.

- It provides high quality services.

- It provides facility of playing online games very easily.

\section{LIMITATIONS OF 5G TECHNOLOGY}

5G technology has a major drawback of higher bit rate which can be controlled by the use of Open Control Protocol (OCP).

\section{APPLICATIONS OF 5G TECHNOLOGY}

- Worldwide networks will provide widespread computing. Users of $5 \mathrm{G}$ technology can connect to the several wireless access technologies simultaneously and can move among any mobile network, Wi-Fi, WAPAN or other technologies may be developed in future without any interruptions. This concept may be further developed into multiple concurrent data transfer path. ${ }^{[3]}$

- Cognitive technology enables different radio technologies to share the allotted spectrum efficiently and can use unused channels without any interference and adapting transmission scheme according to the requirements of the technologies currently sharing the spectrum and make it possible to use the available radio frequency without interfering with other users. ${ }^{[3]}$

- Korean research has suggested radio interface of $5 \mathrm{G}$ communication systems and development program based on beam division multiple access. ${ }^{[3]}$

\section{FURTHER RESEARCH DIRECTIONS}

A new era can be opened in mobile communication by $5 \mathrm{G}$ network technology. The $5 \mathrm{G}$ mobile phones will have better access to different wireless technologies at the same time and the terminal must be able to combine several flows from different technologies. The $5 \mathrm{G}$ mobile phones will act as a tablet PC ${ }^{[7]} 6 \mathrm{G}$ technology hasn't been fully disclosed yet but search phrases like what is $6 \mathrm{G}$ technology, $6 \mathrm{G}$ mobile, and $6 \mathrm{G}$ network are getting more and more popular with progressing new mobile technology.

\section{CONCLUSION}

Mobile phones have become vital part of our daily life. The development of the mobile and wireless networks is going towards higher data rates and all-IP principle. ${ }^{[6]}$ The modern expansion is the consequence of diverse generations. In this paper, we have revised the diverse cohorts of mobile wireless technology and the impression of 5G technologies, its design, types, benefits, restrictions and its applications. The $5 \mathrm{G}$ mobile phone is designed as an open platform on different layers ranging from physical layer up to the application.

\section{REFERENCES}

[1]. S. Venkata Krishna Kumar and Poornima.T.V, "A Study of Wireless Mobile Technology," International Journal of Advanced Research in Computer Science and Software Engineering (IJARCSSE), Volume 4, Issue 1, January 2014.

[2]. Jonathan Rodriguez, "Fundamentals of 5G Mobile Networks," John Wiley \& Sons, Ltd, United Kingdom, 2015. 
[3]. Meenal G. Kachhavay and Ajay P.Thakare, "5G Technology-Evolution and Revolution," International Journal of Computer Science and Mobile Computing (IJCSMC), Volume 3, Issue 3, March 2014.

[4]. Ms. Reshma S. Sapakal and Ms. Sonali S. Kadam, "5G Mobile Technology," International Journal of Advanced Research in Computer Engineering \& Technology (IJARCET), Volume 2, Issue 2, February 2013.

[5]. Olumuyiwa Oludare FAGBOHUN, "Comparative studies on 3G, 4G and 5G wireless technology," IOSR Journal of Electronics and Communication Engineering (IOSR-JECE), Volume 9, Issue 3, May-June 2014.

[6]. Aleksandar Tudzarov and Toni Janevski, "Functional Architecture for 5G Mobile Networks," International Journal of Advanced Science and Technology, Volume 32, July 2011.

[7]. Sapana Singh and Pratap Singh, "Key Concepts and Network Architecture for 5G Mobile Technology," International Journal of Scientific Research Engineering \& Technology (IJSRET), Volume 1, Issue 5, August 2012.

[8]. Puneet Kumar, Er. Manwinder Singh and Prof. J.K.Sharma, "5G Technology of Mobile Communication," International Journal of Electronics and Computer Science Engineering.

\section{BIOGRAPHIES}

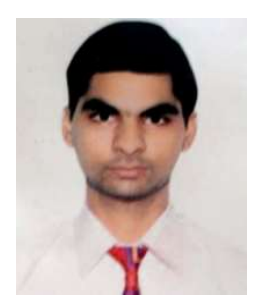

Vyom Bhushan, Final Year Student, Automobile Engineering Dept., IOK College of Engineering, S. P. Pune University, Pune-412208, India

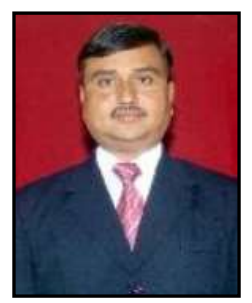

Dr. D. B. Salunke, E\&TC Engineering Dept., S. P. Pune University, Pune412208, India. More than 26 publications in International Publications and Conferences. 